\title{
UTILITY OF COMPUTER MODELLING IN DETERMINATION OF SAFE AVAILABLE EVACUATION TIME
}

\begin{abstract}
The main aim of the paper is to evaluate the primary factors affecting the safe available evacuation time with the utility of computer modelling, namely Consolidated Model of Fire and Smoke Transport (CFAST) computer model by NIST. The traditionally accepted base value of 2.5 minutes, used in many design standards, may not be appropriate due to its very generalised nature. Hence, a multi-criteria analysis is carried out in which four standard fire scenarios (fire growth rates) are modelled in a set of compartments with varying geometry. The simulation results are assessed against a range of critical conditions, including visibility, toxicity and temperature. Obtained safe available evacuation times are then compared to the standardised values used in design. The results show that the standardised times derived from the 2.5-minutes base value are not as conservative as believed; both under-and overprediction have been identified. The outcomes indicate that a review of the standardised available safe evacuation times should be carried out.
\end{abstract}

Keywords: Available safe evacuation time (ASET), $t^{2}-$ fire, CFAST, layer height, toxicity.

\section{Introduction}

Many of fire safety design standards prescribe the maximum allowed length and minimum clear width of escape routes. By adhering to these limits, evacuees are assumed not to be exposed to the harmful effects of fire and smoke and to exit the building prior to the onset of untenable conditions. So logically, the maximum length and minimum width must be calculated for a time period during which tenability is maintained. In fire safety engineering the term Available Safe Evacuation Time (ASET) is used to define this period, however, there is no direct equivalent in prescriptive fire design codes and various other terms may be used, e.g. Maximum Allowed Evacuation Time (MAET) [1]; for the purposes of this paper the term ASET is used, although it does not refer specifically to fire safety engineering design.

In prescriptive or other traditional codes, however, ASET is usually not stated directly as a time value but rather as the above mentioned length and width limits. This ASET value is usually based on the 2.5-minutes clearance time indicated in [2]. In light of the age, premise and significant generalisation of the 2.5-minutes value, forming critical part of fire design standards internationally, there is a need for a review of its validity and applicability.

This paper provides an introduction study of the effect of the most important parameters - compartment geometry and fire dynamics - on the Available Safe Evacuation Time. The selected geometries should demonstrate how the increasing area and height of a compartment and the rate of fire growth affect the onset of tenability limits. Computer modelling, namely CFAST and FDS, is used to calculate the development of the fire and its parameters.

\section{Model description}

A set of rectangular-geometry compartments of varying area and height was modelled in CFAST, a zone computer model. In each compartment, four differently growing fires were simulated in order to assess the impact of compartment geometry and fire properties on the available safe evacuation time.

\footnotetext{
* ${ }^{1}$ Vladimir Mozer, ${ }^{2}$ Jiri Pokorny, ${ }^{3}$ Petr Kucera, ${ }^{1}$ Lubica Vrablova, ${ }^{4}$ Peter Wilkinson

${ }^{1}$ Department of Fire Engineering, Faculty of Security Engineering, University of Zilina, Slovakia

${ }^{2}$ Fire \& Rescue Service, Department of prevention and CNP, Ostrava, Czech Republic

${ }^{3}$ Department of Fire Protection, Faculty of Safety Engineering, Technical University of Ostrava, Czech Republic

${ }^{4}$ Civil Safety and Security Unit, University of Leicester, United Kingdom

E-mail: vladimir.mozer@fbi.uniza.sk
} 


\subsection{Consolidated Model of Fire and Smoke Transport (CFAST) and Fire Dynamics Simulator (FDS)}

CFAST is a two-zone fire model used to calculate the evolving distribution of smoke, fire gases and temperature throughout compartments of a building during a fire. These can range from very small containment vessels on the order of $1 \mathrm{~m}^{3}$ to large spaces on the order of $1000 \mathrm{~m}^{3}$ [3].

The modelling equations used in CFAST take the mathematical form of an initial value problem for a system of ordinary differential equations (ODEs). These equations are derived using the conservation of mass, the conservation of energy (equivalently the first law of thermodynamics), the ideal gas law and relations for density and internal energy. These equations predict as functions of time quantities such as pressure, layer height and temperatures given the accumulation of mass and enthalpy in the two layers. The CFAST model then consists of a set of ODEs to compute the environment in each compartment and a collection of algorithms to compute the mass and enthalpy source terms required by the ODEs [4].

FDS version 6.1.1 (July 10, 2014) [5] and [6], a CFD model by NIST was used for validation in which results from CFAST and more advanced FDS were compared.

\subsection{Compartment geometry and ventilation}

Each simulated compartment comprised an undivided square room with side dimensions selected such that the floor area was $50,100,150$ and $200 \mathrm{~m}^{2}$, depending on the case. In addition, a $200 \mathrm{~m}^{2}$ room divided into four identical $50 \mathrm{~m}^{2}$ rooms was modelled. This scenario was introduced in order to evaluate the impact of partitions on the ASET, as it allows to observe three sizes of a compartment - 50, 150 and $200 \mathrm{~m}^{2}$ - and compare them with their respective undivided counterparts. The layout the divided-compartment scenario is shown in Fig. 1.

Two compartment heights were simulated - 2.7 and $4.5 \mathrm{~m}$; the first represents the clear construction height of a standard office storey, and the second is to represent higher spaces, such as auditoria, assembly halls, etc.
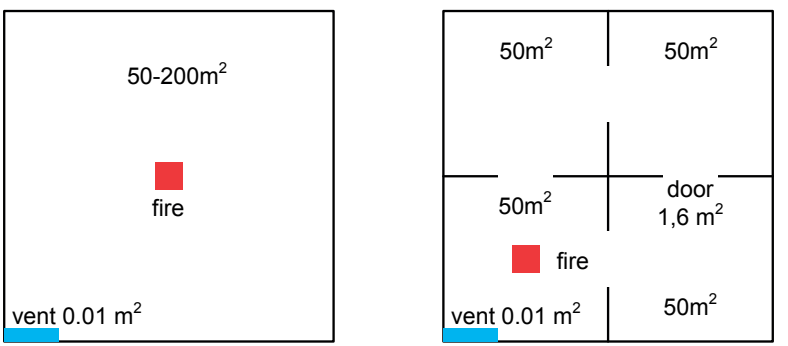

Fig.1 Geometric layout of simulated compartments (undivided left / divided right)
Ventilation was provided only via a slit of $0.01 \mathrm{~m}^{2}$ crosssection area in each case. This way air leakage in and out of the compartment via gaps around doors and other similar paths was simulated. No open windows and doors to the exterior were included in the simulation. It was assumed that the selected temperature tenability limit $\left(120^{\circ} \mathrm{C}\right)$ will not cause damage to the enclosing construction, doors and windows. This assumption was also confirmed in a previous study [7].

In the divided $200 \mathrm{~m}^{2}$ case, additional ventilation between the individual rooms was through four doors. Each door was $2 \mathrm{~m}$ high and $0.8 \mathrm{~m}$ wide, resulting in a total open area of $1.6 \mathrm{~m}^{2}$.Their layout is shown in Fig. 1. The doors remained open for the entire duration of the simulation.

\subsection{Fire scenarios and fuel properties}

Fires are usually described by the time-temperature relation or heat release rate [8]. The basic assumption employed in this study is that only the growth phase of a fire is considered relevant to evacuation. The tenability limits are far exceeded by the time the fire reaches flashover, therefore, it is not needed to consider the phase of fully developed fire when evaluating the safe available evacuation time in the room of fire origin.

During the growth phase, the fire is fuel-bed controlled (well ventilated) and its heat output grows with time. For this purpose the $t^{2}$ - fire model was used in this paper to prescribe the development of the heat release rate (HRR) with time. This model is well established widely used in the fire safety engineering field, see e.g. [9] and [10]. The basic principle of this model is that HRR grows exponentially with time and the intensity of the growth is defined through the fire-growth coefficient $\alpha_{i}$. Four standard fire-growth regimes are defined, depending on the time a fire requires to reach a HRR of $1 \mathrm{MW}$; these are specified in Table 1.

Fire growth regimes for $t^{2}$-fire [9]

Table 1

\begin{tabular}{|l|l|l|l|}
\hline $\begin{array}{l}\text { Fire growth } \\
\text { regime }\end{array}$ & $\begin{array}{l}\text { Time to reach } \\
1 \mathrm{MW}[\mathrm{s}]\end{array}$ & $\begin{array}{l}\text { Coefficient } \alpha_{\mathrm{i}} \\
{\left[\mathrm{kW} \cdot \mathrm{s}^{-2}\right]}\end{array}$ & $\begin{array}{l}\text { Example building } \\
\text { use [11] }\end{array}$ \\
\hline Slow & 600 & 0.00293 & Picture gallery \\
\hline Medium & 300 & 0.01172 & Office \\
\hline Fast & 150 & 0.0469 & Shop \\
\hline Ultra-fast & 75 & 0.1876 & High rack storage \\
\hline
\end{tabular}

For each of the above described compartment geometries, all four fire-growth regimes were modelled. The fire itself had a fixed floor area of $10 \mathrm{~m}^{2}$. Although, in a real fire, the burning area would increase with time, this is not possible to model in the current implementation of CFAST. For this reason, the McCaffrey plume model [4] was used, which is independent of the floor area of the fire. It was found to yield greater plume 
entrainment rates (in agreement with [12]), therefore erring on the side of safety.

Since the incubation time - the period from ignition to sustained growth - is rather variable, ranging from 0 to 100's of seconds, it was not included in the simulation. The HRR grows from $t=0 \mathrm{~s}$ without any delay. Once again, this errs on the side of safety and allows for a wide application of the obtained results.

The fuel was specified as a mixture of wood and polyurethane foam, an approximation of common cellulosic-plastic fuel composition. The ratio was $70 \%$ wood and $30 \%$ polyurethane. Since CFAST and FDS allow specification of a single fuel, the chemical composition, product yields and other properties were calculated as a weighted mean of the respective fractions. All the original properties were taken from SFPE Handbook [10]. The resulting fuel specification is as follows:
Formula: $\mathrm{C}_{4.94} \mathrm{H}_{6.5} \mathrm{O}_{2.4} \mathrm{~N}_{0.3}$
Heat of combustion:
$20390 \mathrm{~kJ} \cdot \mathrm{kg}^{-1}$
Soot yield:
$0.05 \mathrm{~kg} / \mathrm{kg}$
CO yield:
$0.007 \mathrm{~kg} / \mathrm{kg}$

\subsection{Tenability criteria}

When determining the available safe evacuation time, properly selected tenability criteria are of crucial importance. For this study the following quantities were monitored; the associated values represent critical tenability limits:
Critical layer height: $1.9 \mathrm{~m} \mathrm{[13]}$
Smoke OD: $\quad 0.15 \mathrm{~m}^{-1}[10]$
Ambient temperature: $120^{\circ} \mathrm{C}[10]$
Heat radiation: $\quad 2.5 \mathrm{~kW} \cdot \mathrm{m}^{-2}[10]$
CO concentration: $500 \mathrm{ppm} \mathrm{[14]}$
CO2 concentration: $3 \%$ vol. [14]
O2 concentration: $15 \%$ vol. [15]

The critical layer height $(1.9 \mathrm{~m})$ is based on the philosophy presented in CSN 730802 [13] which allows this limit for spaces with a smaller clear height. It also represents a height at which a large proportion of the general population will not be affected by the smoke layer.

Tenability was reviewed on the basis of exceeding at least one of the above listed critical values and simultaneous decrease of the smoke layer below $1.9 \mathrm{~m}$. The only exception is the intensity of heat radiation which is monitored at ground level. If $2.5 \mathrm{~kW} \cdot \mathrm{m}^{-2}$ is exceeded, untenable conditions are reached regardless of the layer height.

\section{Results}

The following Tables 2 to 5 list the available safe evacuation times determined for the individual geometries and fire growth rates. In addition to the ASET values (seconds), each value is also assigned an acronym indicating which of the tenability criteria was exceeded. The acronyms are as follows:

Critical layer height $(\mathrm{H})$; Smoke OD (OD); Ambient temperature $(\mathrm{T})$; Heat radiation $(\mathrm{R})$;

$\mathrm{CO}$ concentration $(\mathrm{CO}) ; \mathrm{CO}_{2}$ concentration $(\mathrm{CO} 2) ; \mathrm{O}_{2}$ concentration $(\mathrm{O} 2)$.

If $(\mathrm{H})$ is listed, then one or more criteria were exceeded prior to the smoke layer decrease to $1.9 \mathrm{~m}$. If other acronyms, except $(\mathrm{R})$, are stated, then the smoke layer decreased below $1.9 \mathrm{~m}$ and the given criterion - (OD), (T), (CO), (CO2), (O2) - was exceeded afterwards. As mentioned previously, the heat radiation criterion ( $\mathrm{R}$ ) is independent of the smoke height, therefore, it states the time at which the critical intensity was exceeded.

Available safe evacuation times for undivided compartments $-2.7 \mathrm{~m}$ height

Table 2

\begin{tabular}{|c|c|c|c|c|}
\hline \multirow{2}{*}{$\begin{array}{c}\text { Floor area } \\
{\left[\mathrm{m}^{2}\right]}\end{array}$} & \multicolumn{4}{|c|}{ Available Safe Evacuation Time (s) } \\
\cline { 2 - 5 } & Slow & Medium & Fast & Ultra-fast \\
\hline 50 & $92(\mathrm{OD})$ & $55(\mathrm{OD})$ & $42(\mathrm{H})$ & $32(\mathrm{H})$ \\
\hline 100 & $109(\mathrm{H})$ & $84(\mathrm{H})$ & $65(\mathrm{H})$ & $49(\mathrm{H})$ \\
\hline 150 & $141(\mathrm{H})$ & $109(\mathrm{H})$ & $84(\mathrm{H})$ & $62(\mathrm{H})$ \\
\hline 200 & $169(\mathrm{H})$ & $130(\mathrm{H})$ & $100(\mathrm{H})$ & $73(\mathrm{H})$ \\
\hline
\end{tabular}

Available safe evacuation times for divided compartments $-2.7 \mathrm{~m}$ height

Table 3

\begin{tabular}{|l|c|c|c|c|}
\hline \multirow{2}{*}{ Room $\left[\mathrm{m}^{2}\right]$} & \multicolumn{4}{|c|}{ Available Safe Evacuation Time (s) } \\
\cline { 2 - 5 } & Slow & Medium & Fast & Ultra-fast \\
\hline Room 1 - fire & $91(\mathrm{OD})$ & $54(\mathrm{H})$ & $42(\mathrm{H})$ & $32(\mathrm{H})$ \\
\hline Room 2 - adjoining & $186(\mathrm{OD})$ & $129(\mathrm{H})$ & $97(\mathrm{H})$ & $71(\mathrm{H})$ \\
\hline Room 3 - adjoining & $186(\mathrm{OD})$ & $129(\mathrm{H})$ & $97(\mathrm{H})$ & $71(\mathrm{H})$ \\
\hline Room 4 - remote & $281(\mathrm{OD})$ & $188(\mathrm{H})$ & $139(\mathrm{H})$ & $102(\mathrm{H})$ \\
\hline
\end{tabular}

Available safe evacuation times for undivided compartments - $4.5 \mathrm{~m}$ height

Table 4

\begin{tabular}{|c|c|c|c|c|}
\hline \multirow{2}{*}{$\begin{array}{c}\text { Floor area } \\
{\left[\mathrm{m}^{2}\right]}\end{array}$} & \multicolumn{4}{|c|}{ Available Safe Evacuation Time (s) } \\
\cline { 2 - 5 } & Slow & Medium & Fast & Ultra-fast \\
\hline 50 & $133(\mathrm{OD})$ & $86(\mathrm{H})$ & $66(\mathrm{H})$ & $50(\mathrm{H})$ \\
\hline 100 & $172(\mathrm{H})$ & $131(\mathrm{H})$ & $101(\mathrm{H})$ & $75(\mathrm{H})$ \\
\hline 150 & $222(\mathrm{H})$ & $169(\mathrm{H})$ & $127(\mathrm{H})$ & $93(\mathrm{H})$ \\
\hline 200 & $266(\mathrm{H})$ & $202(\mathrm{H})$ & $149(\mathrm{H})$ & $108(\mathrm{H})$ \\
\hline
\end{tabular}


Available safe evacuation times for divided compartments $-4.5 \mathrm{~m}$ height

Table 5

\begin{tabular}{|l|l|l|l|l|}
\hline \multirow{2}{*}{ Room $\left[\mathrm{m}^{2}\right]$} & \multicolumn{4}{|l|}{ Available Safe Evacuation Time (s) } \\
\cline { 2 - 5 } & Slow & Medium & Fast & Ultra-fast \\
\hline Room 1 - fire & $133(\mathrm{OD})$ & $86(\mathrm{H})$ & $66(\mathrm{H})$ & $50(\mathrm{H})$ \\
\hline Room 2 - adjoining & $281(\mathrm{OD})$ & $180(\mathrm{OD})$ & $130(\mathrm{H})$ & $94(\mathrm{H})$ \\
\hline Room 3 - adjoining & $281(\mathrm{OD})$ & $180(\mathrm{OD})$ & $130(\mathrm{H})$ & $94(\mathrm{H})$ \\
\hline Room 4 - remote & $425(\mathrm{OD})$ & $282(\mathrm{OD})$ & $192(\mathrm{OD})$ & $134(\mathrm{H})$ \\
\hline
\end{tabular}

The following Tables 6 and 7 list the available safe evacuation times determined for the smallest area of compartment $\left(50 \mathrm{~m}^{2}\right)$ and fire growth rates using two types of fire models (CFAST and FDS).

ASET results from CFAST and FDS - $50 \mathrm{~m}^{2}$ area,

$2.7 \mathrm{~m}$ height compartment

Table 6

\begin{tabular}{|l|c|c|c|c|}
\hline \multirow{2}{*}{ Type of model } & \multicolumn{4}{|c|}{ Available Safe Evacuation Time (s) } \\
\cline { 2 - 5 } & Slow & Medium & Fast & Ultra-fast \\
\hline CFAST & $92(\mathrm{OD})$ & $55(\mathrm{OD})$ & $42(\mathrm{H})$ & $32(\mathrm{H})$ \\
\hline FDS & $94(\mathrm{OD})$ & $56(\mathrm{OD})$ & $32(\mathrm{H})$ & $23(\mathrm{H})$ \\
\hline
\end{tabular}

ASET results from CFAST and FDS - $50 \mathrm{~m}^{2}$ area,

$4.5 \mathrm{~m}$ height compartment

Table 7

\begin{tabular}{|l|c|c|c|c|}
\hline \multirow{2}{*}{ Type of model } & \multicolumn{4}{|c|}{ Available Safe Evacuation Time (s) } \\
\cline { 2 - 5 } & Slow & Medium & Fast & Ultra-fast \\
\hline CFAST & $133(\mathrm{OD})$ & $86(\mathrm{H})$ & $66(\mathrm{H})$ & $50(\mathrm{H})$ \\
\hline FDS & $125(\mathrm{OD})$ & $86(\mathrm{OD})$ & $51(\mathrm{H})$ & $29(\mathrm{H})$ \\
\hline
\end{tabular}

Graphic visualisation of results is possible via SMOKEVIEW. Figure 2 shows a comparison of smoke layer heights and zone interfaces obtained from CFAST and FDS for the $50 \mathrm{~m}^{2}$ compartment with $2.7 \mathrm{~m}$ height and medium fire growth rate. The snapshots are taken at the time when critical conditions were exceeded.
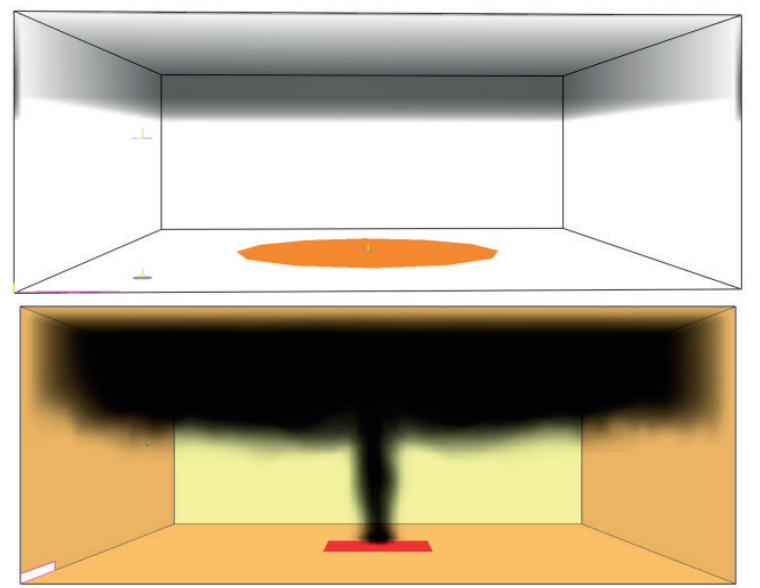

Fig. 2 Visualisation of smoke layer in CFAST (top) and FDS (bottom)

\section{Discussion}

The simulation results from CFAST are evaluated from two points of view - in general and in relation to the $2.5 \mathrm{~min}$ value which is considered as the base safe available evacuation time. Facts which are predictable even without simulation (e.g. shorter time to critical values for smaller compartments, lower ceiling height and greater fire growth rates), are not further discussed in detail.

Based on the simulations carried out, it is possible to make a general statement that, for the given simulation conditions, the layer height and optical density of smoke, were the major limiting criteria; the importance of optical density grew with the fire growth rate. The limiting temperature criterion was usually exceeded after the above criteria (OD and $\mathrm{H}$ ).

The critical $\mathrm{CO}, \mathrm{CO}_{2}$ and $\mathrm{O}_{2}$ concentrations were not the limiting factor in any of the cases. This result is closely tied to the specification of fuel chemistry and individual species assessment. The specification of fuel is arbitrary and was explained in Section 2.3. The Fractional Effective Dose (FED) could be used for a more detailed assessment of critical concentrations and toxic potential of the above gases. In general, the onset of the individual dangerous species concentrations was well after the $\mathrm{OD}, \mathrm{H}$ and $\mathrm{T}$ criteria were exceeded.

In relation to the available safe evacuation time, it may be concluded that for the undivided compartments $(50-200$ $\left.\mathrm{m}^{2}\right)$, untenable conditions were attained in $32 \mathrm{~s}(0.53 \mathrm{~min}$.) - $169 \mathrm{~s}$ (2.81 min.) for the $2.7 \mathrm{~m}$ compartment height and 50 s $(0.83 \mathrm{~min}$.) - $266 \mathrm{~s}$ (4.43 min.) for the $4.5 \mathrm{~m}$ compartment height. A very significant fact is that, for a given fire growth rate, the ASET does not grow linearly with the floor area of the compartment, but slower; for a four-fold increase in floor area the ASET is approximately doubled.

It is apparent that the critical conditions were achieved prior to the base 2.5 min ASET, mainly in the scenarios with smaller floor area and height and higher fire growth rates. ASETs exceeding 2.5 min were established for larger and taller compartments and slower growing fires. This is a logical and more or less expected outcome which confirms the doubts over the robustness of a "generic" ASET value (2.5 $\mathrm{min})$. It is clear that the ASET is affected not only by the occupancy type (purpose group), determining the fire growth rate, but the compartment geometry - area and height - plays also a significant role. Nonetheless, the geometry factor has very little use in the traditional fire codes, both nationally and internationally.

For the divided compartments of $200 \mathrm{~m}^{2}$ floor area, the ASET value intervals were $32 \mathrm{~s}$ (0.53 min.) - $281 \mathrm{~s} \mathrm{(4.68} \mathrm{min.)} \mathrm{and} 50$ $\mathrm{s}(0.83 \mathrm{~min}$.) - $425 \mathrm{~s}$ ( $7.08 \mathrm{~min}$.), for $2.7 \mathrm{~m}$ and $4.5 \mathrm{~m}$ compartment heights, respectively. The spatial division of the compartment causes gradual smoke filling and greater ASET values. The fire location and room configuration plays a significant in this type of scenario. Although, a greater ASET is achieved in the most 
distant room, when compared to an undivided compartment of the same floor area, if egress is available only via the fire room, the greater ASET is of little value. This confirms the importance of two-way escape and dangers associated with inner-room configurations. Essentially, if an inner-room configuration is present the ASET is the value for the entrance room and not that for the inner room. Inner-inner rooms should be avoided at all; a requirement which is not explicitly stated in the Slovak or Czech fire codes. British Approved document B, for example, prohibits such a room configuration.

The comparison of the results from the CFAST zone model and FDS CFD model for the undivided $50 \mathrm{~m}^{2}$ revealed that there is a good agreement across all the monitored criteria. It is, therefore, safe to say that the zone model, although simpler and faster, offers a comparable result precision. For simpler compartment geometries, such as the above, this brings the advantage of reduced computational time, which in turn allows for more a detailed parametric analysis - more scenario variations.

\section{Conclusion}

The fact that the Available Safe Evacuation Time (ASET) is primarily affected by the dynamics of fire and compartment geometry is commonly acknowledged in the fire safety industry. It is, therefore, not in the interest of life safety that fire safety design codes do not incorporate these factors adequately, be it for historical or other reasons.

This study reveals, on a set of simple but representative scenarios, how significant an impact both of these factors have. Although the scenarios cover only a very limited range of areas and heights, $50-200 \mathrm{~m}^{2}$ and $2.7 / 4.5 \mathrm{~m}$, respectively, the difference in ASET for any given fire growth rate is around 300\% and even greater for spatially divided geometries. This variation is not negligible and points out that the historical base ASET value of $2.5 \mathrm{~min}$ should be reviewed in light of these findings; as a minimum fire design codes should account for compartment area and height. At the moment, the Czech and Slovak codes adjust the 2.5 min base ASET for only the effect of purpose group, similarly to the British code [16]. It was also found that ASET does not grow linearly with the floor area of compartment but slower.

Spatial division was found to have a positive effect on ASET, however only when each room has two available directions of escape. It was confirmed that inner-room compartment geometries are not desirable from an escape point of view. Where unavoidable, ASET for the access room should be taken as limiting.

From a tenability point of view, it was found that the smoke layer height and optical density of smoke are the primary factors determining ASET. The results reveal that the smoke optical density criterion is usually the first one to have been exceeded, followed by smoke layer decrease to the critical height. Other tenability criteria were exceeded subsequently.

\section{Acknowledgements}

This work was supported by the Slovak Research and Development Agency under the contract No. APVV-0727-12.

This work was supported by the project of the Ministry of the Interior of the Czech Republic No. VG 20122014074 "Specific Assessment of High Risk Conditions for Fire Safety by Fire Engineering Procedures".

\section{References}

[1] STN 92 0201-1: Fire Safety of Buildings - Part 3. Escape Routes and Evacuation. B.m.: SUTN, 2000.

[2] Post War Building Studies, No. 29: Fire Grading of Buildings - Parts II., III. and IV., Her Majesty's Stationery Office, London, 1952.

[3] PEACOCK, R. D., RENEKE, P. A., FORNEY, G. P.: CFAST - Consolidated Model of Fire Growth and Smoke Transport (Version 6) User's Guide. NIST SP 1041r1. B.m.: National Institute of Standards and Technology, 2013.

[4] PEACOCK, R. D., RENEKE P. A., FORNEY G. P.: CFAST - Consolidated Model of Fire Growth and Smoke Transport (Version 6) Technical Reference Guide. NIST SP 1026r1. B.m.: National Institute of Standards and Technology, 2013.[5] Mc GRATTAN, K. et al: Fire Dynamics Simulator Technical Reference Guide Vol. 1: Mathematical Model. NIST SP 1018, Sixth Edition. B.m.: National Institute of Standards and Technology, 2014.

[6] McGRATTAN, K. et al: Fire Dynamics Simulator User's Guide. NIST SP 1019, Sixth Edition. B.m.: National Institute of Standards and Technology, 2014.[7]MOZER, V.: An Analysis of Factors Affecting Available Safe Escape Time. Advanced Materials Research, vol. 1001, 2014, pp. 267-271, ISSN 1662-8985.

[8] BLAGOJEVICH, M. D.: Time-temperature Curve Definition According to Fuel Type. Communications - Scientific Letters of the University of Zilina, No. 3, 2006, pp. 48-51, ISSN 1335-4205, 2006.

[9] MAYFIELD, C., HOPKIN, D.: Design Fires for Use in Fire Safety Engineering. Bracknell : IHS BRE Press : BRE Trust, ISBN 9781848061521, 2011. 
[10] DINENNO, P. J.: SFPE Handbook of Fire Protection Engineering, $4^{\text {th }}$ ed. Quincy, Mass. : Bethesda, Md: National Fire Protection Association : Society of Fire Protection Engineers, 2008, ISBN 9780877658214.

[11] PD 7974-1: Part 1 Initiation and Development of Fire within the Enclosure of Origin. London: BSI, 2003.

[12] KARLSSON, B., QUINTIERE, J.: Enclosure Fire Dynamics, Boca Raton : Taylor \& Francis : Environmental \& Energy Engineering, 2002, ISBN 9781420050219.

[13] CSN 73 0802: Fire Safety of Buildings - Non-industrial Buildings, Praha : Urad pro technickou normalizaci, metrologii a statni zkusebnictvi, 2009, $122 \mathrm{p}$.

[14] HOSSER, D. L.: Ingenieurmethoden des Brandschutzes. Braunschweig: Vereinigung zur Forderung des Deutschen Brandschutzes e.V., GFPA German Fire Protection Association, 2009, 386 p.

[15] Krajskahygienickastanicese sidlemvPraze:ReducedOxygenLevelsin WorkplaceandtheirEffectonEmployees'Health(inCzech), available online at: http://www.khsstc.cz/ Soubor.ashx?souborID=1104\&typ=application/pdf\&nazev=Sn\%C3\%AD\%C5\%BEen\%C3\%BD\%20 obsah\%20kysl\%C3\%ADku\%20v\%20pracovn\%C3\%ADm\%20prost\%C5\%99ed\%C3\%AD.pdf, accessed on 05/09/2014.

[16] CLG. Approved Document B, vol. 1\&2, 2006, Communities and Local Government. 